Article

\title{
Experimental Study on Frost Height of Round Plate Fin-Tube Heat Exchangers for Mobile Heat Pumps
}

\author{
Moo-Yeon Lee ${ }^{1}$, Yongchan Kim ${ }^{2}$ and Dong-Yeon Lee ${ }^{3, *}$
}

1 Department of Mechanical Engineering, Dong-A University, 37 Nakdong-Daero 550 beon-gil saha-gu, Busan, Korea; E-Mail: mylee@dau.ac.kr

2 Department of Mechanical Engineering, Korea University, Anam-Dong, Sungbuk-Ku, Seoul 136-713, Korea; E-Mail: yongckim@korea.ac.kr

3 School of Mechanical Engineering, Yeungnam University, 280 Daehak-Ro, Gyeongsan, Gyeongbuk 712-749, Korea

* Author to whom correspondence should be addressed; E-Mail: dylee@ynu.ac.kr; Tel.: +82-53-810-2461; Fax: +82-53-810-4627.

Received: 23 May 2012; in revised form: 4 June 2012 / Accepted: 9 July 2012 /

Published: 10 September 2012

\begin{abstract}
The objective of this study was to provide experimental data that could be used to predict frost growth and frost performance of a round plate fin-tube heat exchanger for low temperature heat pumps used in zero emission vehicles under cold weather conditions. In this study, round plate fin-tube heat exchangers were tested with variation of the fin space, air flow rate, relative humidity, and inlet air temperature. Frost height was measured and considered with the boundary layer interruption between fins. Frost height for $8.0 \mathrm{~mm}$ of fin space was increased by approximately $91.9 \%$ with an increase of relative humidity from $50.0 \%$ to $80.0 \%$. The growth rate of frost height at $1.2 \mathrm{~m}^{3} / \mathrm{min}$ was observed to be $13.0 \%$ greater than that at $0.8 \mathrm{~m}^{3} / \mathrm{min}$. Finally, the variation of the blockage ratio with fin space would be an important reference for designing advanced heat exchangers that operate under cold weather conditions.
\end{abstract}

Keywords: frost; heat exchanger; heat pump; height; round plate fin

\section{Nomenclature}

$F_{f} \quad$ Fin space $(\mathrm{mm})$

$T$ Temperature $\left({ }^{\circ} \mathrm{C}\right)$

$L \quad$ Appropriate characteristic length ( $\mathrm{mm})$

$X_{\mathrm{s}}$ Frost layer height $(\mathrm{mm})$ 


$\begin{array}{lll}\text { Greek symbols } & x \quad \mathrm{X} \text {-axis } \\ \delta & \text { Boundary layer thickness } & y \quad \mathrm{Y} \text {-axis } \\ r & \text { Radius (mm) } & \\ \gamma & \text { Blockage ratio }(\%) & \text { Subscripts } \\ u & \text { Velocity component in } x \text { direction } & \mathrm{c} \text { current } \\ & (\mathrm{mm} / \mathrm{s}) & \text { crit critical } \\ v & \text { Velocity component in } y \text { direction } & \mathrm{s} \text { surface } \\ & (\mathrm{mm} / \mathrm{s}) & \infty \text { free stream }\end{array}$

\section{Introduction}

The formation of frost is a general physical phenomenon that occurs under cold weather conditions in air to air and air to refrigerant heat exchangers, such as the evaporator of an air conditioning system, heat exchangers in a refrigeration system, heat pumps, in the storage of cryogenic liquids, and on the Earth's surface in winter. Accordingly, frost formation and growth is an important problem that is often encountered in refrigeration systems, especially in domestic and commercial refrigerators and freezers, heat pumps used in cold weather conditions, and recently mobile heat pumps for vehicles. As humid air passes over the cold fin of the heat exchanger, which is below the freezing point, water condenses onto the cold plate surface. Moisture molecules migrate to frosted surface and the void of frost layer leads to frost growth and densification of frost layer. Frost layer acts as an insulating layer between the fins and the air. In addition, frost blocks the air path, causing an increased pressure drop and a decrease in the air flow rate. Usually frost is removed periodically to improve the efficiency of operation. This normally involves heating the surface to melt frost, a costly operation since energy is required to melt frost and the heat exchanger is out of operation during the process, although several researchers suggested the non-costly defrosting techniques for heat pump systems at a laboratory stage as mentioned in Huang et al. [1] and Byrne et al. [2].

Hence frost properties have to be exactly predicted in order to build a numerical model of frost growth. Density and thermal conductivity, which affect the mass and heat transfer rate under cold weather conditions, are interrelated and are known to be functions of the air velocity, temperature, surface temperature, and air humidity ratio. Numerous experimental and theoretical investigations on frosting have been performed over a long period of time because the prediction of frost growth with time in the heat exchanger is directly related with frost heat transfer rate, the amount of frost, and the defrosting time. Jones and Parker [3] studied frost formation with varying environmental parameters. They developed a model for prediction of frost growth. The trends predicted by their model were in good agreement with the test data. However, their models did not consider molecular diffusion in frost layer. Brian et al. [4] developed a frost growth model which considered frost layer as a porous substance. Neiderer [5] studied frosting and defrosting effects on heat transfer coils. Kondepudi and O'Neal [6] studied on the effect of frost growth on the performance of louvered finned tube heat exchangers. O'Neal et al. [7] studied on the impact of a hydrophobic coating on frost buildup and the defrost performance of a heat pump heat exchanger. Rite and Crawford [8] studied experimentally the 
effects of various parameters on the rate of frost formation on the domestic refrigerator-freezer finned tube heat exchanger coil with $5.1 \mathrm{~mm}$ of fin space. Hayashi [9] found that the amount of frosting gets larger at the entrance of an air flow, in agreement with the general results of other papers. Schneider [10] simulated frost height by balancing the heat transfer rate between vapor diffusivity on frost surface and thermal conductivity between frost layers of a parallel plate heat exchanger. Sanders [11] studied the influence of frost formation and defrosting on the performance of air coolers. Sommers and Jacobi $[12,13]$ studied the air-side heat transfer enhancement of a refrigerator evaporator that used the winglet vortex generation technique under both non-frosting and frosting conditions. Xia et al. [14] studied frost, defrost, and refrost and its impact on the air-side thermal-hydraulic performance of louvered-fin, flat-tube heat exchangers. Xie et al. [15] developed multiple correlations on the air-side heat transfer and friction characteristics of fin-tube heat exchangers by parametric study. Shao et al. [16] showed the comparison of heat pump performance using fin and tube and microchannel heat exchangers under frosting conditions. Hong et al. [17] studied frost growth of the louvered fins of a micro channel heat exchanger. Moallem et al. [18] reported experimental measurements on frosting performance of the micro channel heat exchangers for heat pump system. These researches were mostly concerned with general heat exchangers in refrigeration systems and the HVAC system in simple geometries.

However, the majority of papers on frosting in air conditioning systems, heat pumps, and refrigeration systems, which have more complex geometries such as fin-and-tube heat exchangers, are quite limited due to the large number of variables, the difficulty in quantitative analysis of frost, and the thermodynamic properties of humid air. The round plate fin-tube heat exchanger having large fin pitch ranging from 4.0 to $12.0 \mathrm{~mm}$ is considered in this study, which is much larger than the fin pitch of heat exchangers used for the residential and commercial heat pump systems (normally, fin pitch ranging from 1.4 to $2.0 \mathrm{~mm}$ ). This is because frosting problem is very important in adoption of the heat exchanger used in the heat pump system for zero emission vehicles such as electric vehicles, fuel cell electric vehicles, hybrid electric vehicles, etc. So, the round plate fin-tube heat exchangers with large fin pitches might be used for zero emission. The reason is that the use of heat pumps instead of a PTC (positive temperature coefficient) heater for heating in a cabin under cold weather conditions has been studied for the longer driving ranges of the above-mentioned vehicles [19]. In addition, there could be an easy defrosting water disposal option through an outdoor installation of the outdoor heat exchanger for mobile heat pumps because of the round fin configurations. In this respect, new and precise studies on frosting behavior of round plate fin tube heat exchangers under cold weather conditions are necessary. The objective of this study is to investigate frost behavior and frost growth of a heat exchanger with a round plate fin configuration and large fin pitch under cold weather conditions. Finally, these experimental data could be used for designing an effective heat exchanger of a heat pump system to be used in zero emission vehicles. 


\section{Experimental Setup}

\subsection{Test Specifications}

A schematic of the experimental setup used to measure frost height during frost growth on the tested heat exchangers is shown in Figure 1. The test equipments were installed in a psychrometric chamber to provide a pre-controlled ambient temperature. The psychrometric chamber was maintained at $5.0^{\circ} \mathrm{C}$ using an air-handling unit including a cooling coil, a heating coil, and a humidifier. The air temperature entering the test section was adjusted by using an electric resistance heater installed at the entrance of the flow chamber. The humidity was maintained at a set point by adjusting the power input to an ultrasonic humidifier. For measurement convenience, an ethylene glycol-water mixture was utilized as a refrigerant which passed through aluminum tubes. The temperature of the ethylene glycol-water mixture was constantly controlled properly by a constant temperature bath including a chiller and an electric heater. Air temperatures of test coils at the inlet and outlet were measured by arithmetically averaging the values obtained with twelve thermocouples installed in a uniform grid at each location. Frost layer surface temperature during frost growth was measured using an infrared thermometer with an accuracy of $\pm 0.5^{\circ} \mathrm{C}$. Frost height was measured using a high performance digital cam-coder and a micro-scale measurement device with an accuracy of $\pm 0.001 \mathrm{~mm}$. The thermocouples were calibrated to an accuracy of $\pm 0.1^{\circ} \mathrm{C}$. The absolute humidity was measured using a chilled mirror dew point sensor with an accuracy of $\pm 0.2{ }^{\circ} \mathrm{C}$. The air flow rate was measured using a nozzle in an open wind tunnel to an estimated accuracy of $\pm 2.0 \%$. The pressure drop across the tested heat exchanger was measured using a differential pressure transducer with an accuracy of $\pm 1.0 \%$. The refrigerant flow rate was measured using a Coriolis effect flow meter with an uncertainty of $\pm 0.2 \%$ of the reading.

Figure 2 shows the schematic diagram of the tested round fin tube heat exchanger. Table 1 shows the test conditions and specifications in this experiment. Test conditions are considering the real operating conditions of a heat exchanger for mobile heat pumps under winter season used in this study. Especially, inlet air temperatures were chosen by reflecting effects of the waste heat from the electric devices of zero emission vehicles under winter season. The round plate fin-tube heat exchangers were tested by varying the air flow rate, relative humidity, fin space, and inlet air temperature. The tested heat exchangers were designed to allow slip space in the front end module (FEM) in the vehicles. The FEM consisted of outdoor heat exchangers (condenser or evaporator), radiators for electric devices and stacks, and a cooling fan used at the front of zero emission passenger vehicles. The diameters of the tube and the round fin were $8.2 \mathrm{~mm}$ with the tube thickness of $0.5 \mathrm{~mm}$ thickness and $23.0 \mathrm{~mm}$ with the fin thickness of $0.15 \mathrm{~mm}$, respectively. Fins were mechanically expanded and coupled with tubes by a fin-tube press machine. Fin spaces were varied from $4.0 \mathrm{~mm}$ to $12.0 \mathrm{~mm}$ considered as heat exchanger usage in the mobile heat pump for zero emission vehicles. Inlet air temperature, inlet refrigerant temperature, and refrigerant mass flux were kept constant in the experiments. In order to observe frost growth and height, a top-of-the-range cam-coder was used to measure frost height on the round plate fin at a real scale. Frost height was measured by micrometer with an accuracy of $0.001 \mathrm{~mm}$. All test conditions and specifications were selected to reflect the use of the heat exchanger for a mobile heat pump in cold weather conditions. Especially, in this study, the temperature of the ethylene glycol-water 
mixture was chosen for reflecting the lowest evaporating temperature, which could be operated in the mobile heat pump.

Figure 1. Schematic diagram of the test set-up.

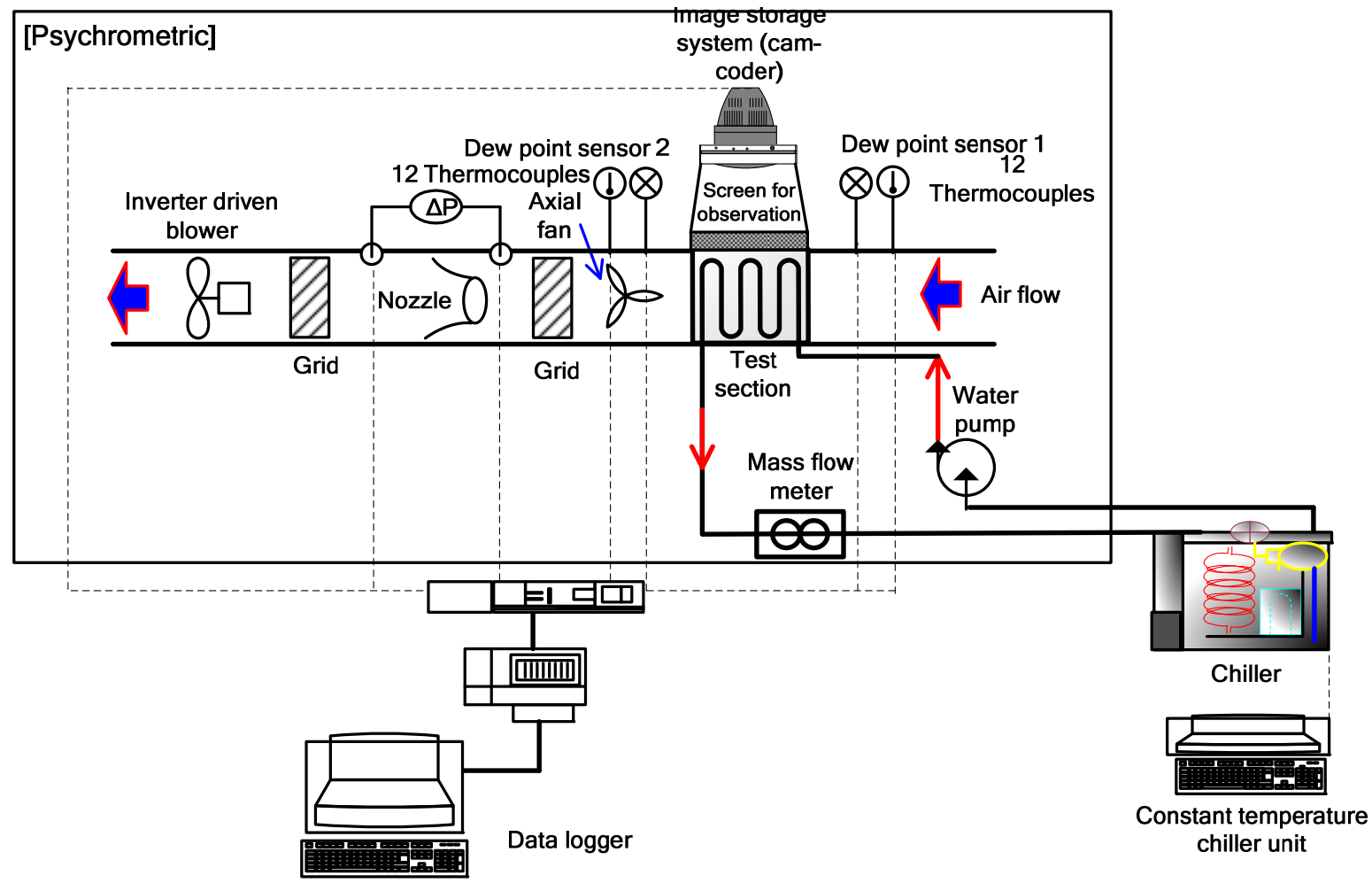

\subsection{Frost Height Measurement}

Frost height was tested for varying air flow rate, relative humidity, and inlet air temperature. Frost height of the tested heat exchanger was measured at the middle fin in first tube of the round plate fin-tube heat exchanger having 2 rows and 2 columns in series because the deviation of frost height at all fins of first tube can be negligible. Namely, frost height measurement location was situated on a circle of a diameter that was half the diameter of the fin and frost height at the fin was a direct distance from center point of the fin surface to end point of frost (column). The measurement location of frost height is $5.75 \mathrm{~mm}$ from the center of the round plate fin as shown in Figure 2. Frost at each fin in the first tube grew as nearly uniform thickness because air flow through the fins was uniform. In addition, variations of the surface roughness of frost with time were not considered in this study because of the relatively large interval time. Frost growth patterns were observed using a high performance digital cam-coder at the middle fin of the tested heat exchanger. Frost height was measured every 10 minutes until 100 minutes. Effect of a surface coating on the defrosting water disposal of the tested round fin tube heat exchanger was not considered in this study. In addition, temperature of the ethylene glycol-water mixture was constantly controlled during the test. In this study, all measured frost height and growth were observed at the round plate fin. In addition, the frost pattern evolution was observed: it started by a crystal growth period and reached a frost layer growth period without reaching the frost layer full growth period as defined by Lee et al. [20]. 
Figure 2. Specifications and configuration of the round plate fin-tube heat exchanger. (a) Round plate fin and tube specification; (b) Heat exchanger configuration and frost height measurement location.

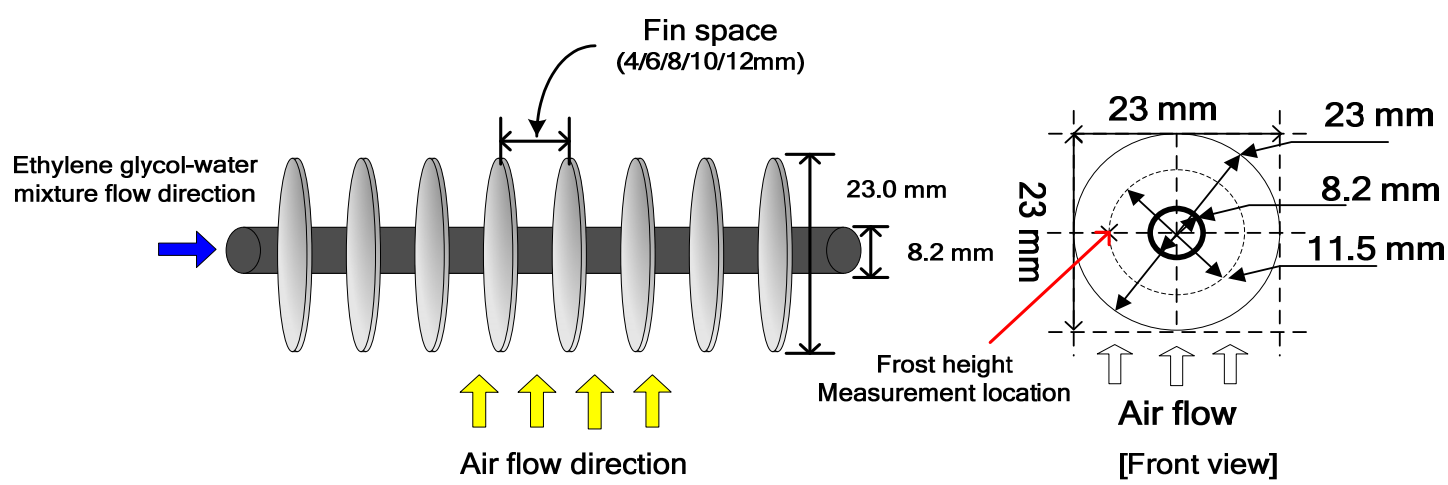

(a)

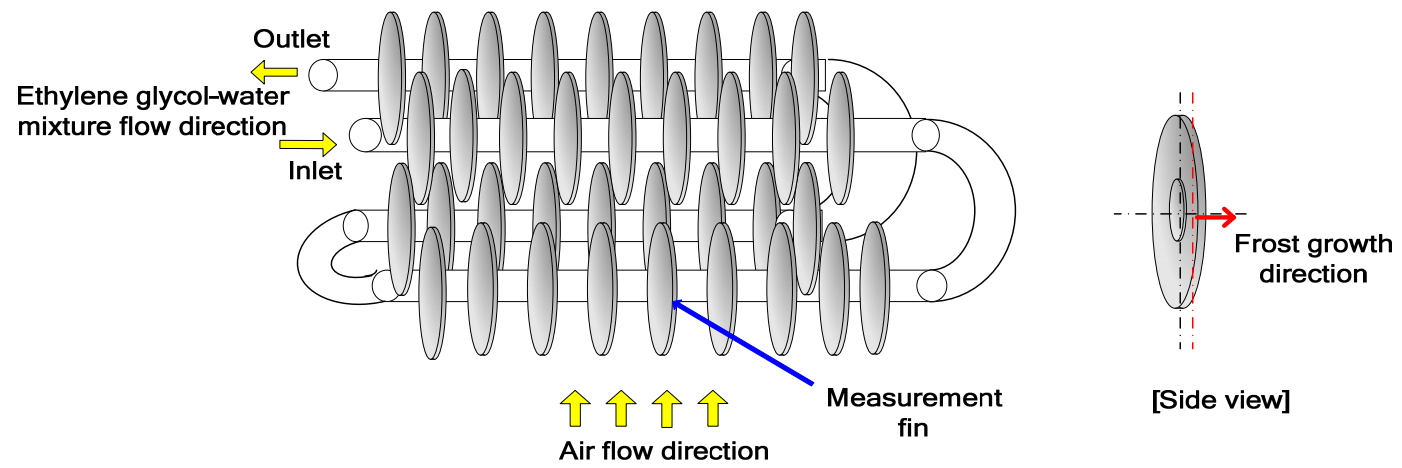

(b)

Table 1. Test conditions and specifications.

\begin{tabular}{ll}
\hline Parameter & Value \\
\hline Fin space $(\mathrm{mm})$ & $4.0 / 6.0 / 8.0 / 10.0 / 12.0$ \\
Fin diameter $(\mathrm{mm})$ & 23.0 \\
Fin thickness $(\mathrm{mm})$ & 0.15 \\
Tube outer diameter $(\mathrm{mm})$ & 8.2 \\
Tube thickness $(\mathrm{mm})$ & 0.5 \\
Tube length $(\mathrm{mm})$ & 650.0 \\
Materials for a fin and a tube & Aluminum \\
Inlet air temperature $\left({ }^{\circ} \mathrm{C}\right)$ & $5.0 / 8.0 / 11.0$ \\
Inlet air relative humidity $(\%)$ & $50 / 60 / 70 / 80$ \\
Airflow rate $\left(\mathrm{m}^{3} /\right.$ min $)$ & $0.6 / 0.8 / 1.0 / 1.2$ \\
Ethylene glycol-water mixture inlet temperature $\left({ }^{\circ} \mathrm{C}\right)$ & -15.0 \\
\hline
\end{tabular}




\section{Results}

\subsection{Boundary Layer}

Figure 3 shows the definition of the boundary layer of the round plate fins used in this study. The boundary layer thickness was determined by solving the continuity, momentum, and energy equation. Governing equations and boundary conditions can be found in Incropera and Dewitt [21]. The appropriate boundary layer conditions were expressed by Equation (1). Air boundary conditions are considered as free stream.

$$
\begin{aligned}
& u(x, 0)=v(x, 0)=0 \text { and } u(x, \infty)=u_{\infty} \\
& T(x, 0)=T_{s} \text { and } T(x, \infty)=T_{\infty}
\end{aligned}
$$

Figure 3(a) shows the schematic of the boundary layer between the round plate fins. Boundary layer interruption between the fins should be considered because it caused the heat transfer coefficient to significantly decrease. To enhance the heat transfer coefficient of the tested heat exchanger, the boundary layer interruption between the fins should be prevented and the developed boundary layer along the fins between the tubes should be broken as mentioned by Lee [22]. Also, the boundary layer thickness increases with the increase of the plate length, resulting in the decrease of the heat transfer coefficient as mentioned by Kim and Kim [23]. Leading edge of the boundary layer formation in the round plate fin was changed along the contour of the round plate fin as shown in Figure 3(b). The boundary layer length and thickness was changed with the contour shape of the round plate fin as given in Equation (2). $L_{x, \text { crit, }}$ which is the distance after occurrence of the boundary layer interruption between the fins, in Equation (3) was the position of a fully developed boundary layer, or the distance from the leading edge at which transition begins. $L_{x, \mathrm{c}}$ is the occurrence point of the boundary layer interruption between the fins.

$$
\begin{gathered}
L_{x}=x_{o}+\left(r-\sqrt{r^{2}-y^{2}}\right) \\
L_{x, \text { crit }}=L_{x, c}+\left(r-\sqrt{r^{2}-y^{2}}\right)
\end{gathered}
$$

\subsection{Frost Growth}

Figure 4(a) shows frost height as the fin space is varied from $4.0 \mathrm{~mm}$ to $12.0 \mathrm{~mm}$ at an inlet air temperature of $5.0{ }^{\circ} \mathrm{C}$, relative humidity of $70.0 \%$, air flow rate of $1.0 \mathrm{~m}^{3} / \mathrm{min}$ and refrigerant temperature of $-15.0^{\circ} \mathrm{C}$. Frost height for the $8.0 \mathrm{~mm}$ fin space showed a similar rate of increase during the first step of 10 minutes because boundary layer interruption theoretically did not occur at over $7.0 \mathrm{~mm}$ of fin space during the tests. As frost continued to grow over 25.0 minutes, frost growth rate in each fin space differed because of the boundary layer interruption by frost growth. Frost growth rate for the $8.0 \mathrm{~mm}$ fin space was lower compared with other fin spaces because the boundary layer interruption occurred at the beginning of frost formation. Theoretically, frost growth rate was affected by the fin space as mentioned by Mon and Gross [24]. However, frost height in the case of the larger fin space of $10.0 \mathrm{~mm}$ was less affected by the fin space because the boundary layer interruption was delayed. Figure 4(b) shows the blockage ratio with the variation of the fin space. Frost blockage ratio 
was defined as Equation (3), suggested by Lee et al [25]. Frost blockage ratio between the fins was defined as the rate of decrease of the air flow path due to the increase in frost height with time. Frost blockage ratio increased with decreasing fin space. Therefore, knowledge of frost blockage ratio would be an important reference for the design of an advanced heat exchanger to operate under cold weather conditions. Frost blockage ratio decreased on average by $26.1 \%$ with the rise of the fin space from $6.0 \mathrm{~mm}$ to $12.0 \mathrm{~mm}$. Therefore the design of the fin space in a heat exchanger is a key parameter when considering the operation time under frosting conditions. In addition, the blocking of the air flow area at smaller fin pitches was more accelerated with frost growth.

$$
\gamma=2 \frac{X_{s}}{F_{f}} \cdot 100(\%)
$$

Figure 3. Boundary layer of the round plate fins. (a) Schematic of the boundary layer between the fins; (b) Configurations of the round plate fin.

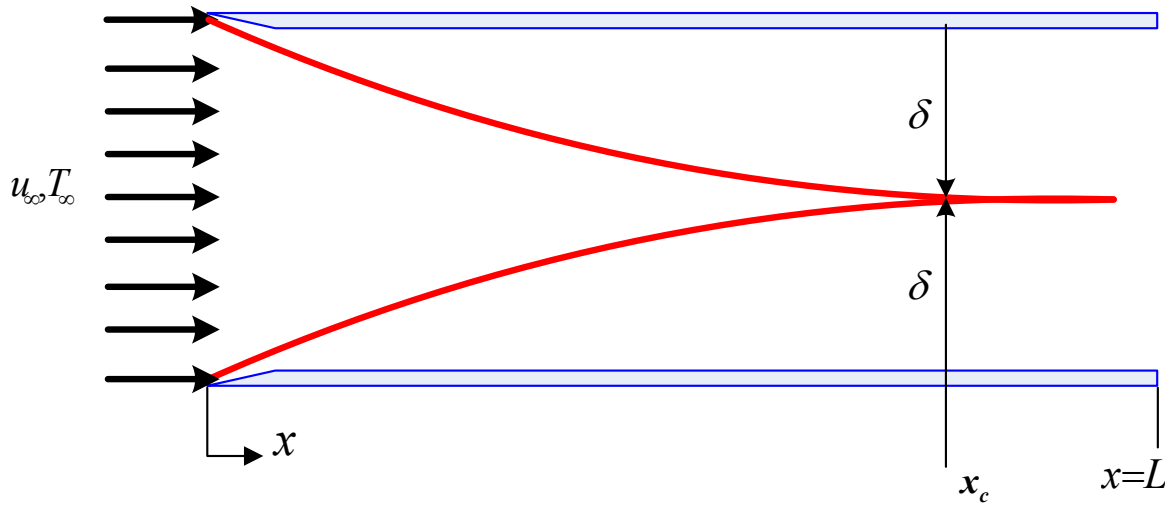

(a)

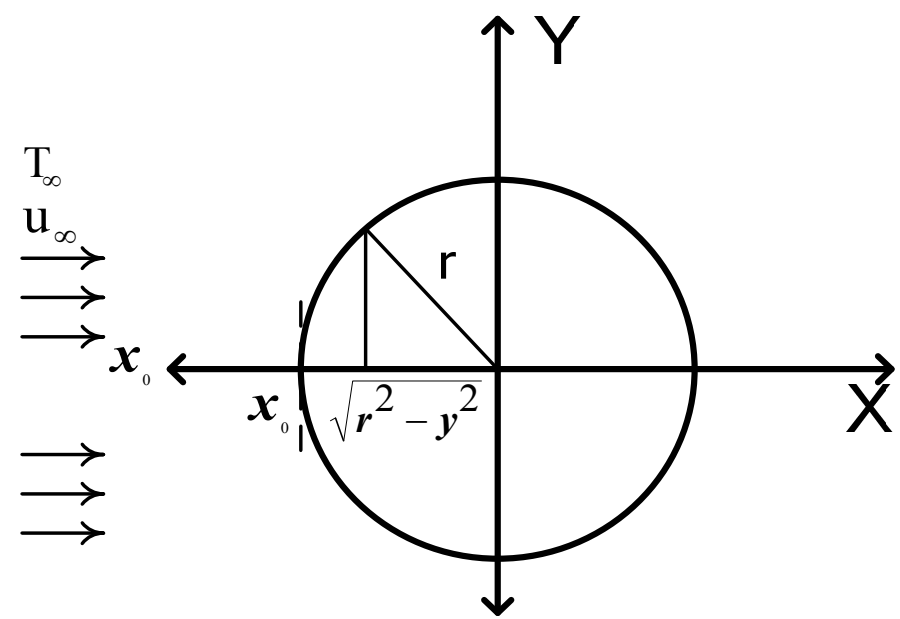

(b) 
Figure 4. Frost height with variation of the fin space. (a) Frost height; (b) Blockage ratio.

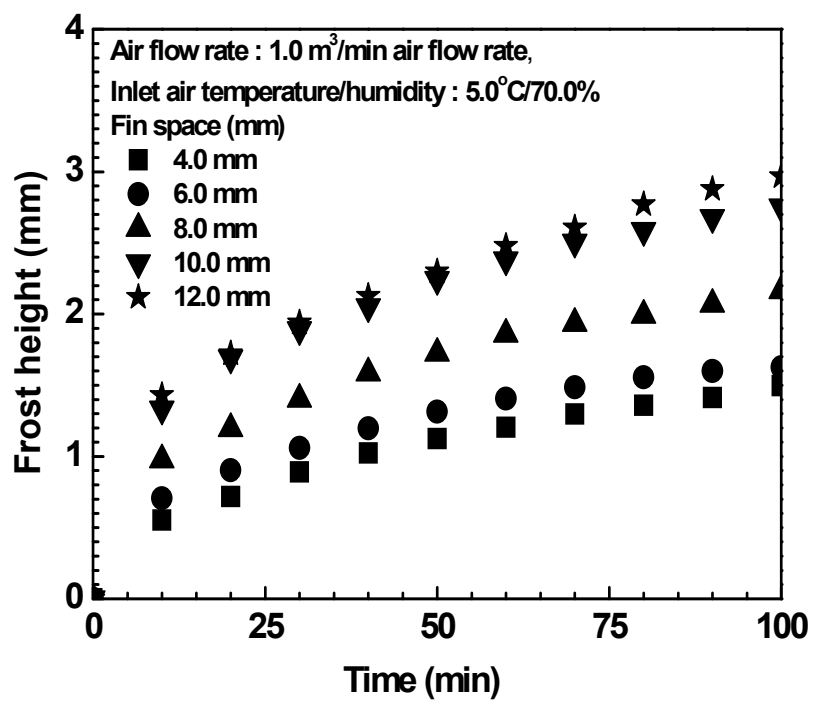

(a)

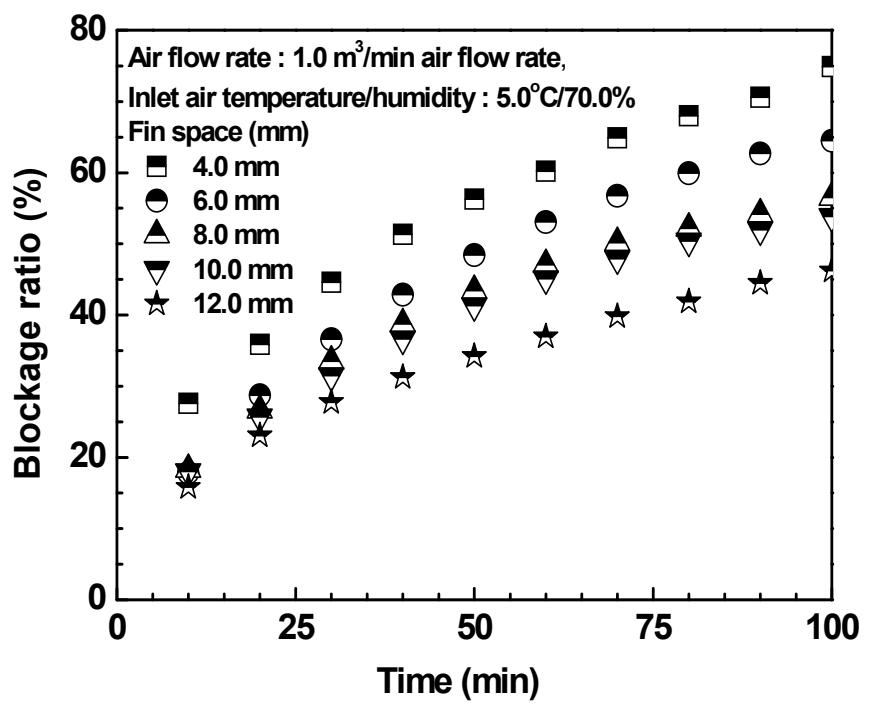

(b)

Figure 5 shows frost height with the variation of the relative humidity of the inlet air for a fin space of $10.0 \mathrm{~mm}$, inlet air temperature of $5.0^{\circ} \mathrm{C}$, air flow rate of $1.0 \mathrm{~m}^{3} / \mathrm{min}$ and refrigerant temperature of $-15.0^{\circ} \mathrm{C}$. Frost height at each relative humidity increased proportionally with time. Frost growth rate at a relative humidity ranging from $50.0 \%$ to $70.0 \%$ showed a similar increasing rate with time but frost growth rate at a relative humidity of $80.0 \%$ increased steeply for the first 40 minutes then grew uniformly. Frost height at $80.0 \%$ relative humidity was $91.9 \%$ greater than that at $50.0 \%$ relative humidity because humidity ratio at $80.0 \%$ relative humidity was $51.0 \%$ greater than that at $50.0 \%$ relative humidity.

Figure 5. Frost height with the variations of the relative humidity.

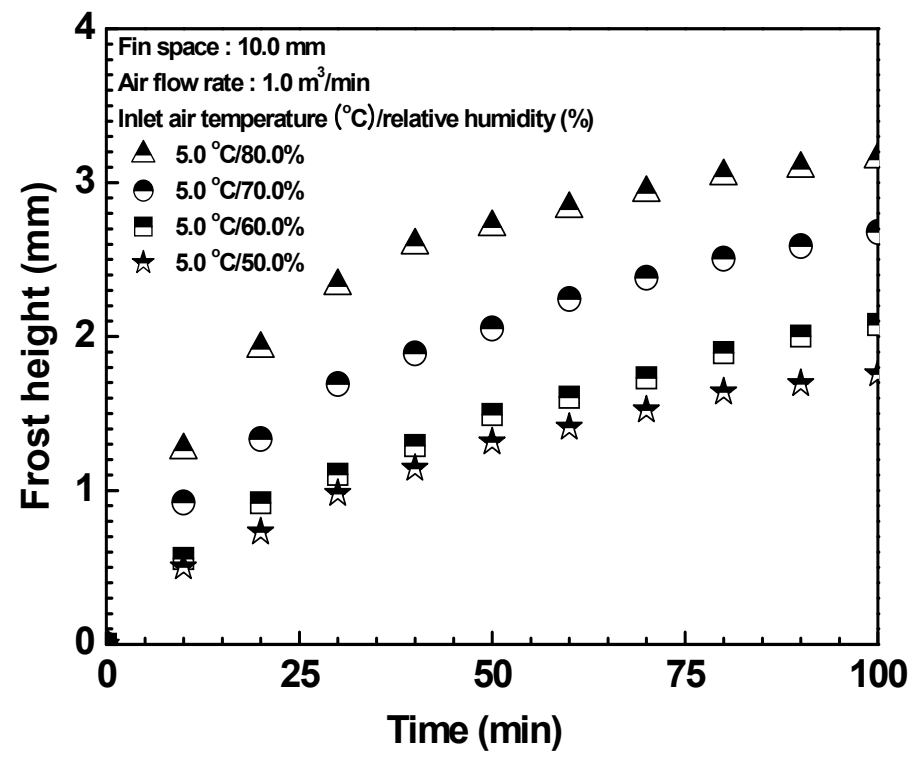


Figure 6 shows frost height with the variations of the air flow rates from $0.8 \mathrm{~m}^{3} / \mathrm{min}$ to $1.2 \mathrm{~m}^{3} / \mathrm{min}$ for a fin space of $10.0 \mathrm{~mm}$, inlet air temperature of $5.0{ }^{\circ} \mathrm{C}$, relative humidity of $70.0 \%$ and refrigerant temperature of $-15.0^{\circ} \mathrm{C}$. Generally, frost thickness increased slightly with air flow rate (or Reynolds number) because of rises in the heat and mass transfer rates with increased air flow rate on the fin surface. The reason is that both the mass deposition rate of water vapor and the density of frost layer increased with increasing Reynolds number as mentioned by Sahin [26]. The author reported that these two properties, almost offsetting each other, yielded an almost unchanged frost thickness. However, there is not yet fully elucidated as there are a number of conflicting data sets: some authors claim that a higher Reynolds number yields a higher frost layer, and some argue the opposite. Both maybe correct in view of the compensatory effect between both, since one of the properties (frost density or deposition rate of mass of water vapor) may be superior to the other under different conditions. Accordingly, in Figure 6, frost height increased with increasing air flow rate because of the increase of the heat and mass transfer rates, although the difference of the increasing rate of frost height was not important. Frost grew steeply until $1.5 \mathrm{~mm}$ of frost height at all air flow rates, but the increasing rate of frost height decreased because of the boundary layer interruptions between the fins with frost growth. The rate of increase of frost height at $1.2 \mathrm{~m}^{3} / \mathrm{min}$ was observed to be $13.0 \%$ greater than that at $0.8 \mathrm{~m}^{3} / \mathrm{min}$. This is because the decreasing rates of the air flow rate with time at $1.2 \mathrm{~m}^{3} / \mathrm{min}$ and $0.8 \mathrm{~m}^{3} / \mathrm{min}$ were $25.0 \%$ and $15.8 \%$, respectively. As a result, a compensatory effect between both, as mentioned above, appeared in the result in Figure 6.

Figure 6. Frost height with the variations of the air flow rate.

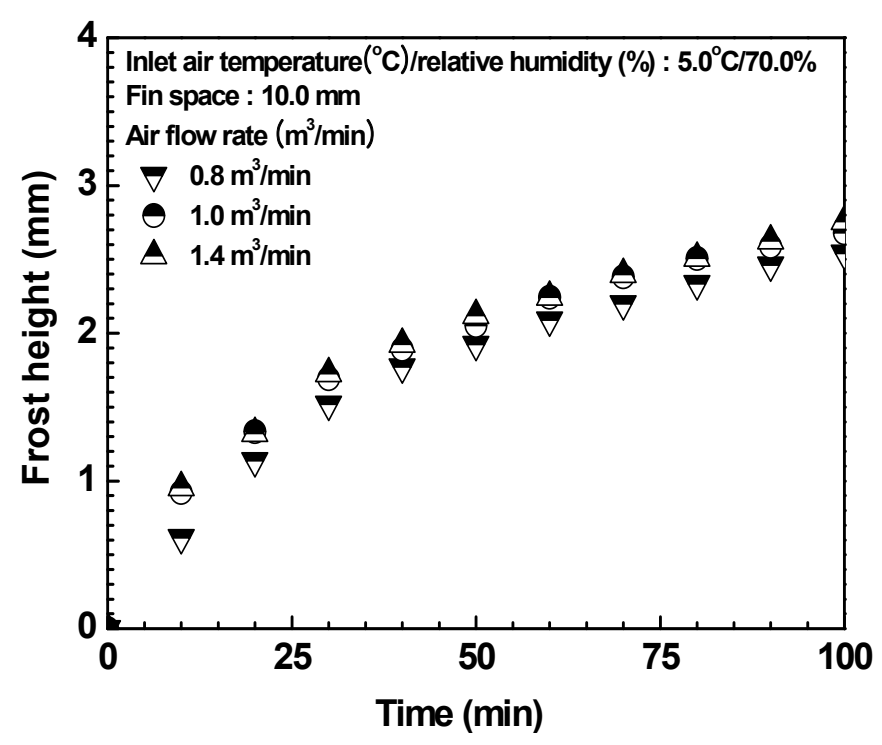

Figure 7 shows frost height with variations of the inlet air temperature at fin space of $10.0 \mathrm{~mm}$, refrigerant temperature of $-15.0{ }^{\circ} \mathrm{C}$, and air flow rate of $1.0 \mathrm{~m}^{3} / \mathrm{min}$. Frost height at an inlet air temperature of $11.0^{\circ} \mathrm{C}$ was $38.5 \%$ greater than that at the inlet air temperature of $5.0{ }^{\circ} \mathrm{C}$. However frost height at inlet air temperature of $11.0^{\circ} \mathrm{C}$ was $4.5 \%$ greater than that of the inlet air temperature of $8.0^{\circ} \mathrm{C}$. This is because the humidity ratio increased with the increase of the inlet air temperature under same relative humidity but the increasing rate of humidity ratio decreased with the inlet air temperature increases. The increasing rate of the humidity ratio at inlet air temperatures from $5.0{ }^{\circ} \mathrm{C}$ to $11.0{ }^{\circ} \mathrm{C}$ and 
from $8.0{ }^{\circ} \mathrm{C}$ to $11.0{ }^{\circ} \mathrm{C}$ were $125.0 \%$ and $50.0 \%$, respectively. Finally, major parameters affected by frost height were the fin space, relative humidity, inlet air temperature, and air flow rate in a row. These trends appeared in the results of Lee et al. [27]. Moreover, the fin space was critically related to the boundary layer interruption with frost growth and air flow rate reduction with time. In order to develop a more precise frost growth model, the boundary layer interruption between fins should be considered to predict frost density with frost growth.

Figure 7. Frost height with the variations of the inlet air temperature.

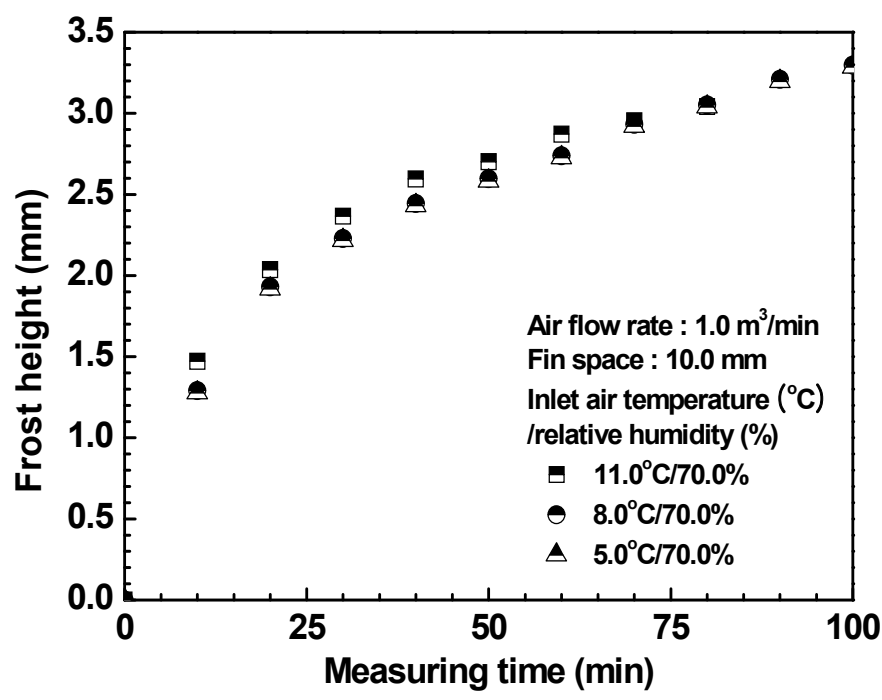

\section{Summary and Conclusion}

Frost height and frost growth rate on the round plate fin-tube heat exchanger, which could be used as the heat exchanger of a heat pump in a zero emission vehicle, as well as in a refrigeration system or an HVAC system in various industries, were experimentally considered. Frost height was affected by the relative humidity, inlet air temperature, and air flow rate. The fin pitch was critically related to boundary layer interruption with frost growth. The variation of the blockage ratio with fin space would be an important reference for designing advanced heat exchangers that operate under cold weather conditions.

(i) Frost height for $8.0 \mathrm{~mm}$ of fin space was constantly increased during the first 10 minutes because the boundary layer interruption theoretically did not occur for a fin space during the tests.

(ii) Frost height increased by approximately $91.9 \%$ with an increase of relative humidity from $50.0 \%$ to $80.0 \%$. Frost height increased by approximately $13.0 \%$ with an increase of the air flow rate from $0.8 \mathrm{~m}^{3} / \mathrm{min}$ to $1.2 \mathrm{~m}^{3} / \mathrm{min}$.

(iii) Frost height at $70.0 \%$ relative humidity increased by $38.5 \%$ with the increase of the inlet air temperature from $5.0^{\circ} \mathrm{C}$ to $11.0^{\circ} \mathrm{C}$. However, frost height at $11.0^{\circ} \mathrm{C}$ inlet air temperature increased to $4.5 \%$ greater than that of the $8.0^{\circ} \mathrm{C}$ inlet air temperature.

\section{Acknowledgments}

This research was supported by the Yeungnam University research grants in 2011. 


\section{References}

1. Huang, D.; Li, Q.; Yuan, X. Comparison between hot-gas bypass defrosting and reverse-cycle defrosting methods on an air-to-water heat pump. Appl. Energy 2009, 86, 1697-1703.

2. Byrne, P.; Miriel, J.; Lénat, Y. Experimental study of an air-source heat pump for simultaneous heating and cooling, Part 2: dynamic behaviour and two-phase thermosiphon defrosting technique. Appl. Energy 2011, 88, 3072-3078.

3. Jones, B.W.; Parker, J.D. Frost formation with varying environmental parameters. J. Heat Transfer 1975, 97, 255-259.

4. Brian, P.I.; Reid, R.C.; Shah, Y.T. Frost deposit on cold surfaces. Ind. Eng. Chem. Environ. 1969, 9, 375-380.

5. Niederer, D.H. Frosting and defrosting effects on coil heat transfer. ASHRAE Trans. 1976, 82, $467-473$.

6. Kondepudi, S.N.; O'Neal, D.L. The effect of frost growth on the performance of louvered finned tube heat exchangers. ASHRAE Trans. 1989, 93, 258-274.

7. O’Neal, D.L.; Bryant, J.A.; Parker, B. Impact of hydrophobic coating on frost buildup and defrost performance of a heat pump heat exchanger. In Proceedings of the 45th Oji International Seminar, Tomakomai, Japan, September 1997; pp. 181-187.

8. Rite, R.W.; Crawford, R.R. The effect of frost growth on the performance of domestic refrigerator-freezer finned tube heat exchanger coils. ASHRAE Trans. 1991, 97, 428-437.

9. Hayashi, Y.; Aoki, A.; Adachi, S.; Hori, K.; Study of frost properties correlating with frost formation types. J. Heat Transfer 1977, 99, 239-245.

10. Schneider, H.W. Equation of growth rate of frost formation on the performance of a parallel plate heat exchanger. Int. J. Heat Mass Transfer 1978, 21, 1019-1024.

11. Sanders, C.T. The influence of frost formation and defrosting on the performance of air coolers. Ph.D. Thesis, Delft Technical University, Delft, The Netherlands, October 1974.

12. Sommers, A.D.; Jacobi, A.M. Air-side heat transfer enhancement of a refrigerator evaporator using vortex generation. Int. J. Refrig. 2005, 28, 1006-1017.

13. Sommers, A.D.; Jacobi, A.M. Heat transfer enhancement by winglet-type vortex generator array in compact fin-and-tube heat exchangers. Int. J. Refrig. 2008, 31, 87-97.

14. Xia, Y.; Zhong, Y.; Hrnjak, P.S.; Jacobi, A.M. Frost, defrost, and refrost and its impact on the air-side thermal-hydraulic performance of louvered-fin, flat-tube heat exchangers. Int. J. Refrig. 2006, 29, 1066-1079.

15. Xie, G.; Wang, Q.; Sunden, B. Parametric study and multiple correlations on air-side heat transfer and friction characteristics of fin-and-tube heat exchangers with large number of large-diameter tube rows. Appl. Therm. Eng. 2009, 29, 1-16.

16. Shao, L.L.; Yang, L.; Zhang, C.L. Comparison of heat pump performance using fin-and-tube and microchannel heat exchangers under frost conditions. Appl. Energy 2010, 87, 1187-1197.

17. Hong, T.; Moallem, E.; Cremaschi, L.; Fisher, D.E. Measurements of frost growth on louvered folded fins of micro-channel heat exchangers Part 1: Experimental methodology. ASHRAE Trans.

2012, 118, 1-7. 
18. Moallem, E.; Cremaschi, L.; Fisher, D.E.; Padhmanabhan, S. Experimental measurements of the surface coating and water retention effects on frosting performance of micro-channel heat exchangers for heat pump systems. Exp. Therm. Fluid Sci. J. 2012, 39, 176-186.

19. Cho, C.W.; Lee, H.S.; Won, J.P.; Lee, M.Y. Measurement and evaluation of heating performance of heat pump systems using wasted heat from electric devices for an electric bus. Energies 2012, 5, 658-669.

20. Lee, M.Y.; Kang, T.H.; Joo, Y.J.; Kim, Y.C. Heat transfer characteristics of spirally-coiled circular fin-tube heat exchanger under frosting conditions. Int. J. Refrig. 2011, 34, 328-336.

21. Incropera, F.P.; Dewitt, D.P. Fundamentals of Heat and Mass Transfer, 4th ed.; John Wiley \& Sons: Hoboken, NJ, USA, 2002.

22. Lee, M.Y. Heat and mass transfer characteristics of a spirally-coiled circular fin tube heat exchanger. Ph.D. Thesis, Korea University, Seoul, Korea, February 2010.

23. Kim, Y.H.; Kim, Y. Heat transfer characteristics of flat plate finned-tube heat exchangers with large fin pitch. Int. J. Refrig. 2005, 28, 851-858.

24. Mon, M.S. Numerical investigation of air-side heat transfer and pressure drop in circular finnedtube heat exchangers. Ph.D. Thesis, Technische Universität Bergakademie Freiberg, Freiberg, Germany, February 2003.

25. Lee, K.S.; Lee, T.H.; Kim, W.S. An experimental study on the effects of design factors for the performance of fin-tube heat exchanger under cold weather conditions. Trans. KSME 1995, 19, 2657-2666.

26. Sahin, A.Z. An experimental study on the initiation and growth of frost formation on a horizontal plate. Exp. Heat Transfer 1994, 7, 101-119.

27. Lee, S.H.; L, M.Y.; Won, Y.J.; Kim, Y. Frost growth characteristics of spirally-coiled circular fin-tube heat exchangers, Int. J. Refrig. 2012, submitted.

(C) 2012 by the authors; licensee MDPI, Basel, Switzerland. This article is an open access article distributed under the terms and conditions of the Creative Commons Attribution license (http://creativecommons.org/licenses/by/3.0/). 